\title{
SISTEM PAKAR IDENTIFIKASI DEFISIENSI UNSUR HARA PADA TANAMAN KOPI MENGGUNAKAN METODE CERTAINTY FACTOR BERBASIS WEB
}

\author{
Muhammad Eka ${ }^{*}$, Novita Anggraini \\ UNIVERSITAS NAHDLATUL ULAMA SUMATERA UTARA, JL. Brigjend H. A.Manaf Lubis / \\ Gaperta Ujung No.2 Medan, Telp : 061 - 80026202 \\ muhammadeka@yahoo.com
}

\begin{abstract}
As the third largest coffee producing country in the world after Brazil and Vietnam, Indonesia is able to produce at least 748 thousand tons or 6.6\% of coffee production in 2012. Of this amount, Robusta coffee production reached more than 601 thousand tons $(80.4 \%)$ and arabica coffee production reached more than 147 thousand tons (19.6\%).The area of coffee plantation in Indonesia reaches 1.3 million hectares (ha) with Robusta coffee plantation area reaches 1 million ha and arabica coffee plantation area reaches 0,30 ha. The use of technology in the cultivation of coffee cultivation in Indonesia, especially smallholder plantations is still minimal technology. Expert system approach by using certainty factor method to overcome uncertainty in identifying nutrient deficiency in coffee plant try to give solution that can be used by coffee farmer especially in smallholder plantation in sidical area of karo regency of north sumatera. By doing a direct observation of the leaves of coffee plants and ensure the symptoms of nutrient deficiency what actually happens in the coffee plant it is with this expert system of certainty of nutrient deficiencies can be known in detail without having to consult directly to the expert. Thus the fertilization process can be done properly, so it will affect the cost of production to a minimum.
\end{abstract}

Keywords: Identification of nutrients, expert system, certainty factor

\begin{abstract}
abstrak
Sebagai negara penghasil kopi terbesar ketiga di dunia setelah Brasil dan Vietnam, Indonesia mampu memproduksi sedikitnya 748 ribu ton atau 6,6\% dari produksi kopi duniapada tahun 2012. Dari jumlah tersebut, produksi kopi robusta mencapai lebih dari 601 ribu ton $(80,4 \%)$ dan produksi kopi arabika mencapai lebih dari 147 ribu ton (19,6\%).Luas lahan perkebunan kopi di Indonesia mencapai 1,3 jutahektar(ha) dengan luas lahan perkebunan kopi robusta mencapai 1 juta ha dan luas lahan perkebunan kopi arabika mencapai 0,30 ha.Penggunaan teknologi dalam budidaya penanaman kopi di Indonesia terutama perkebunan rakyat masih minim teknologi. Pendekatan sistem pakar dengan menggunakan metode certainty factor untuk mengatasi ketidak pastian dalam mengidentifikasi defisiensi unsur hara pada tanaman kopi mencoba memberikan solusi yang dapat digunakan para petani kopi khususnya di perkebunan rakyat didaerah sidikalang kabupaten tanah karo sumatera utara. Dengan melakukan pengamatan langsung dari daun tanaman kopi dan memastikan gejala kekurangan unsur hara apa yang sebenarnya terjadi pada tanaman kopi tersebut maka dengan sistem pakar inilah
\end{abstract}


kepastian terhadap kekurangan unsur hara tersebut bisa diketahui secara detail tanpa harus berkonsultasi langsung kepada pakarnya. Dengan demikian proses pemupukan bisa dilakukan dengan tepat, sehingga akan mempengaruhi biaya produksi seminimal mungkin.

Kata kunci : Identifikasi unsur hara, sistem pakar, certainty factor

\section{PENDAHULUAN}

Sistem pakar (expert system) adalah sistem yang berusaha mengadopsi pengetahuan manusia ke komputer, agar komputer dapat menyelesaikan masalah seperti yang biasa dilakukan oleh para ahli. Sistem pakar yang baik dirancang agar dapat menyelelasikan suatu permasalahan tertentu dengan meniru kerja dari para ahli [1] sedangkan Menurut [2] secara umum sistem pakar adalah sistem yang berusaha mengadopsi pengetahuan manusia ke komputer, agar komputer dapat menyelesaikan masalah seperti yang biasa dilakukan oleh ahli.

Faktor kepastian (certainty faktor) menyatakan kepercayaan dalam sebuah kejadian (fakta atau hipotesis) berdasarkan bukti atau penilaian pakar. Faktor kepastian diperkenalkan oleh Shortliffe Buchanan dalam pembuatan MYCIN pada tahun 1975 untuk mengakomodasi ketidakpastian pemikiran seorang pakar. Team pengembang MYCIN mencatat bahwa seorang dokter sering kali menganalisa informasi yang ada dengan ungkapan seperti : mungkin, kemugkinan besar, hampir pasti. Oleh sebab itu team MYCIN menggunakan metode certainty factor (CF) guna menggambarkan tingkat keyakinan pakar terhadap permasalahan yang sedang dihadapi [3] Dan [4] Certainty Faktor (CF) adalah untuk mengakomodasi ketidakpastian pemikiran (inexact reasoning) seorang pakar yang di usulkan oleh Shortliffe dan Buchanan pada tahun 1975

Penggunaan teknologi dalam budidaya penanaman kopi di Indonesia terutama perkebunan rakyat masih minim teknologi. Pendekatan sistem pakar dengan menggunakan metode certainty factor untuk mengatasi ketidak pastian dalam mengidentifikasi defisiensi unsur hara pada tanaman kopi mencoba memberikan solusi yang dapat digunakan para petani

\section{METODOLOGI PENELITIAN}

Metodologi penelitian adalah sekumpulan peraturan, kegiatan, dan prosedur yang digunakan oleh pelaku suatu disiplin ilmu. Metodologi juga merupakan analisis teoritis mengenai suatu cara atau metode. Penelitian merupakan suatu penyelidikan yang sistematis untuk meningkatkan sejumlah pengetahuan, juga merupakan suatu usaha yang sistematis dan terorganisasi untuk menyelidiki masalah tertentu yang memerlukan jawaban.

Tahapan analisa sistem pakar dimaksudkan untuk mengalisa data - data yang di dapatkan langsung di lapangan untuk selanjutnya di buat aplikasi sistem pakar untuk mengidentifikasi defisiensi keurangan unsur hara pada tanaman kopi menggunakan metode Certainly Factor. Sistem pakar akan di bangun 
berdasarkan analisa penerapan teori sehingga aplikasi yang akan dibangun bisa sejalan, sehingga jika diperiksa secara manual maupun dengan program akan didapatkan kemungkinan hasil defisiensi unsur hara yang tidak jauh berbeda. Adapun data defisiensi unsur hara pada tanaman kopi yang bisa disimpulkan dari hasil survey langsung dilokasi kebun tanaman kopi arabika di tanah karo sumatera utara oleh seorang pakar adalah sebagai berikut :

a. Nitrogen (N)

Tanaman yang mengalami defisiensi unsur $\mathrm{N}$ akan mengalami gejala klorosis pada daun muda dan klorotik pada daun tua. Pada umumnya terjadi pada daun muda yang berubah warna menjadi hijau pucat. Pertumbuhan tunas juga terhambat saat kekurangan $\mathrm{N}$, secara keseluruhan pertumbuhan tanaman akan menurun hingga 50-75 \% dibandingkan dengan tanaman yang memiliki cukup hara.
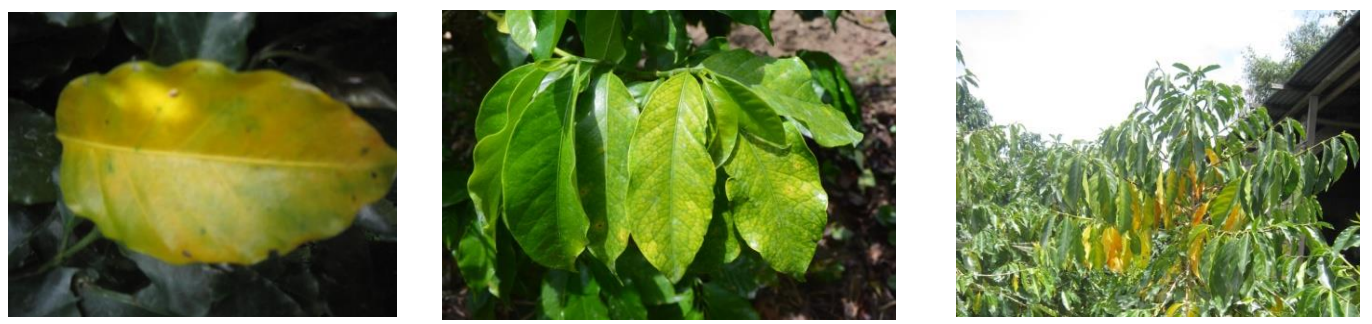

Gambar 1. Gejala Defisiensi Unsur N di Lapangan

b. Fosfor $(\mathrm{P})$

Gejala defisiensi $\mathrm{P}$ terjadi pada daun tua, tulang daun berwarna kuning terang. Selanjutnya hanya menyisakan sedikit bagian daun yang masih berwarna hijau gelap di antara pertulangan daun. Gejala lanjut mulai muncul bercak kecoklatan yang merupakan tanda matinya sel jaringan daun yang dapat melebar. Pertumbuhan akar juga terhambat.

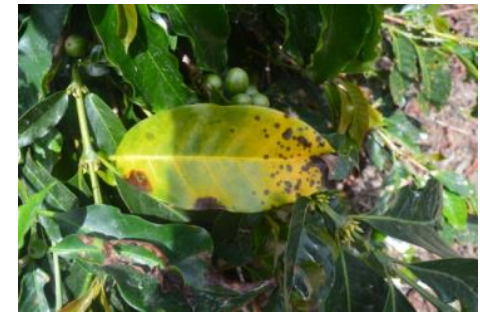

c. Kalium (K)

\section{Gambar 2. Gejala Defisiensi Unsur P di Lapangan}

Gejala defisiensi $\mathrm{K}$ terjadi pada daun tua. Bagian tepi daun awalnya menguning diikuti dengan munculnya bintik coklat (nekrotik) yang menandakan sel jaringan mati. Kemudian bintik melebar disepanjang tepi daun yang mengalami kecoklatan dengan tepi gelap (jaringan daun telah mati) yang dikelilingi oleh warna kuning (lapisan sel daun yang belum mati). Namun, Bagian pertulangan daun tetap berwarna hijau. 

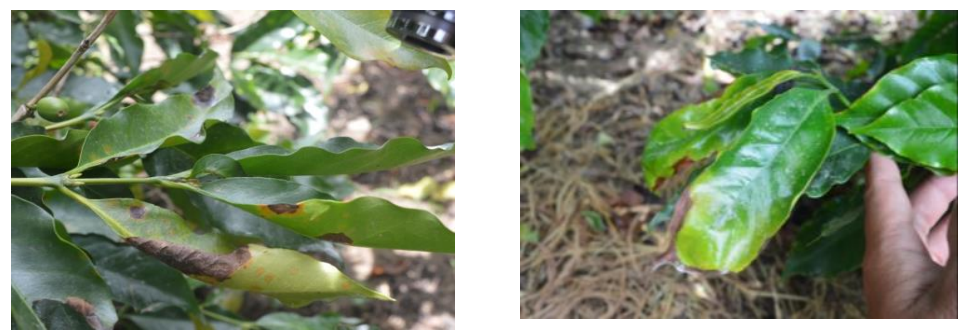

\section{Gambar 3. Gejala Defisiensi Unsur K di Lapangan}

Dari uraian seorang pakar dapatlah disimpulkan beberapa gejala yang nantinya digunakan membangun sistem pakar dengan menggunakan metode Certainly Factor, adapun beberapa gejala tersebut antara lain :

a. Klorosis pada daun muda dan klorotik pada daun tua

b. Daun muda yang berubah warna menjadi hijau pucat

c. Pertumbuhan tunas akan terhambat

d. Tulang daun tua akan menjadi kuning terang

e. Menyisakan sedikit daun yang berwarna hijau gelap diantara pertulangan daun

f. Muncul bercak kecoklatan tanda matinya sel jaringan daun yang dapat melebar

g. Perumbuhan akar akan terhambat

h. Bagian tepi daun tua akan menguning diikuti dengan munculnya bintik coklat (nekrotik)

i. Bintik melebar disepanjang tepi daun dengan tepi gelap yang dikelilingi warna kuning

j. Namun bagian pertulangan daun tetap berwarna hijau

\subsection{Menentukan Bobot Nilai Certainly Factor}

Penentuan nilai bobot Certainly Factor merupakan tahapan dalam menentukan nilai kepercayaan dan ketidakpercayaan pada setiap gejala yang terjadi pada pertumbuhan daun tanaman kopi. Tahap awal yang harus dilakukan seorang pakar adalah dengan mengetahui konsep penilaian metode Certaity Factor. Adapun konsep penilain metodeCeratainty Factoryang dimaksud adalah dengan menggali berdasarkan hasil diskusi dengan pengusul II sebagai pakar tanaman yaitu ibu Novita Anggraini S.Hut. M.Sc didapatlah nilai dari interpretasi "term" dari pakar menjadi nilai MB/MD tertentu :

\begin{tabular}{|l|l|}
\hline Certain Term & MB/MD \\
\hline Tidak tahu / tidak ada & $0.0 \mathrm{~s} / \mathrm{d} 0.2$ \\
Mungkin & $0.2 \mathrm{~s} / \mathrm{d} 0.4$ \\
Kemungkinan besar & $0.5 \mathrm{~s} / \mathrm{d} 0.6$ \\
Hampir pasti & $0.7 \mathrm{~s} / \mathrm{d} 0.8$ \\
Pasti & $0.9 \mathrm{~s} / \mathrm{s} 1$ \\
\hline
\end{tabular}


Tahap selanjutnya pakar akan memberikan nilai bobot Certainty Factor terhadap gejala - gejala defisiensi unsur hara seperti yang telah dijabarkan sebelumnya.

Tabel 1. Nilai Bobot Certainty Factor pada Gejala defisiensi Unsur Hara

\begin{tabular}{|l|l|c|c|}
\hline No. & \multicolumn{1}{|c|}{ Gejala } & $\begin{array}{c}\text { Nilai } \\
\text { Kepastian }\end{array}$ & $\begin{array}{c}\text { Nilai } \\
\text { Ketidakpastian }\end{array}$ \\
\hline 1 & Klorosis pada daun muda dan klorotik pada daun tua & 1 & 0.2 \\
\hline 2 & Daun muda yang berubah warna menjadi hijau pucat & 0.8 & 0.3 \\
\hline 3 & Pertumbuhan tunas akan terhambat & 1 & 0.3 \\
\hline 4 & Tulang daun tua akan menjadi kuning terang & 1 & 0.3 \\
\hline 5 & $\begin{array}{l}\text { Menyisakan sedikit daun yang berwarna hijau gelap } \\
\text { diantara pertulangan daun }\end{array}$ & 0.8 & 0.5 \\
\hline 6 & $\begin{array}{l}\text { Muncul bercak kecoklatan tanda matinya sel jaringan } \\
\text { daun yang dapat melebar }\end{array}$ & 1 & 0.2 \\
\hline 7 & Perumbuhan akar akan terhambat & 0.6 & 0.2 \\
\hline 8 & $\begin{array}{l}\text { Bagian tepi daun tua akan menguning diikuti dengan } \\
\text { munculnya bintik coklat (nekrotik) }\end{array}$ & 1 & 0.2 \\
\hline 9 & $\begin{array}{l}\text { Bintik melebar disepanjang tepi daun dengan tepi } \\
\text { gelap yang dikelilingi warna kuning }\end{array}$ & 1 & 0.2 \\
\hline 10 & Namun bagian pertulangan daun tetap berwarna hijau & 0.8 & 0.2 \\
\hline
\end{tabular}

\section{HASIL DAN PEMBAHASAN}

\subsection{Flowchart Klasifikasi Jenis Defisiensi Unsur Hara Pada Tanaman Kopi}

Tahap ini akan membahas alur diagnose defisiensi unsur hara pada tanaman kopi berdasarkan hasil pemberian nilai bobot Certanty Factor yang telah diberikan pakar yang tetra pada tabel 1. tabel nilai bobot Certanty Factor pada gejala defisiensi unsur hara pada tanaman kopi. Alur diagnose ini dilakukan agar sistem pakar yang akan dirancang menghasilkan hasil d227iagnose yang akurat dan terpercaya. Berikut akan dijabarkan alur 5 diagnose gejala defisiensi unsur hara pada tanaman kopi :

1. Alur diagnosis jenis defisiensi Nitrogen $(\mathrm{N})$

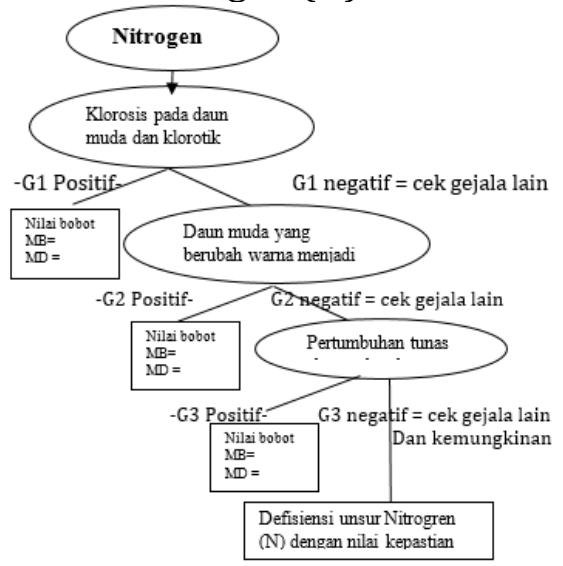

Gambar 4. Alur diagnosis jenis defisiensi Nitrogen (N) 


\subsection{Arsitektur Sistem Pakar}

Arsitektur sistem pakar yang akan dibangun nantinya merupakan penyederhanaan beberapa komponen diantaranya :Knowledge Base, Database, Inference Engine, User interface dan Explanation facilities. Adapun gambaran mengenai arsitektur sistem pakar tersebut adalah sebagai berikut:

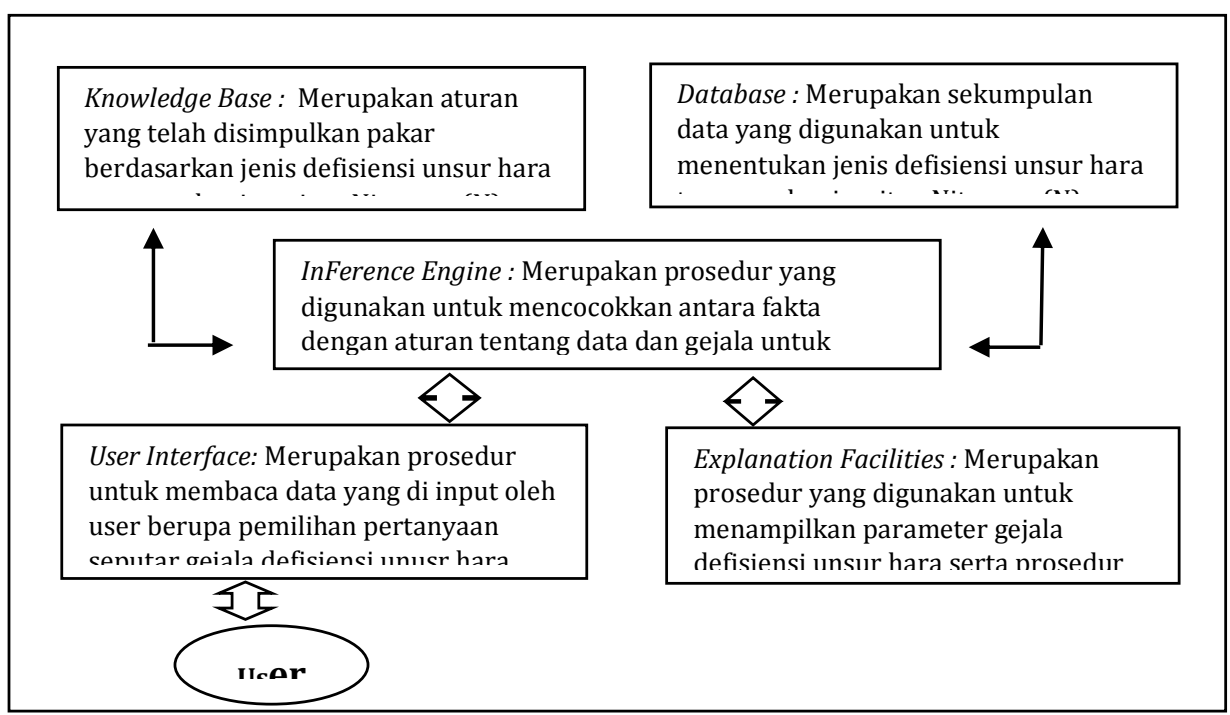

Gambar 5. Arsitektur Sistem Pakar

\subsection{Flowchart Diagnosa Defisiensi Unsur Hara Pada Tanaman Kopi}

Setelah tahap analisa kebutuhan diagram alir selesai dan sudah didefenisikan dengan jelas maka tahapan selanjutnya adalah membuat Flowchartdiagnosa defisiensi unsur hara pada tanaman kopi.Flowchart ini nantinya di gunakan untuk mengembangkan mesin Inference Engine dengan menggunakan metode Certainty Factor dalam mendiagnosa defisiensi Unsur hara pada tanaman kopi. Berikut akan dijelaskan flowchart diagnosa defisiensi unsur hara pada tanamna kopi : 


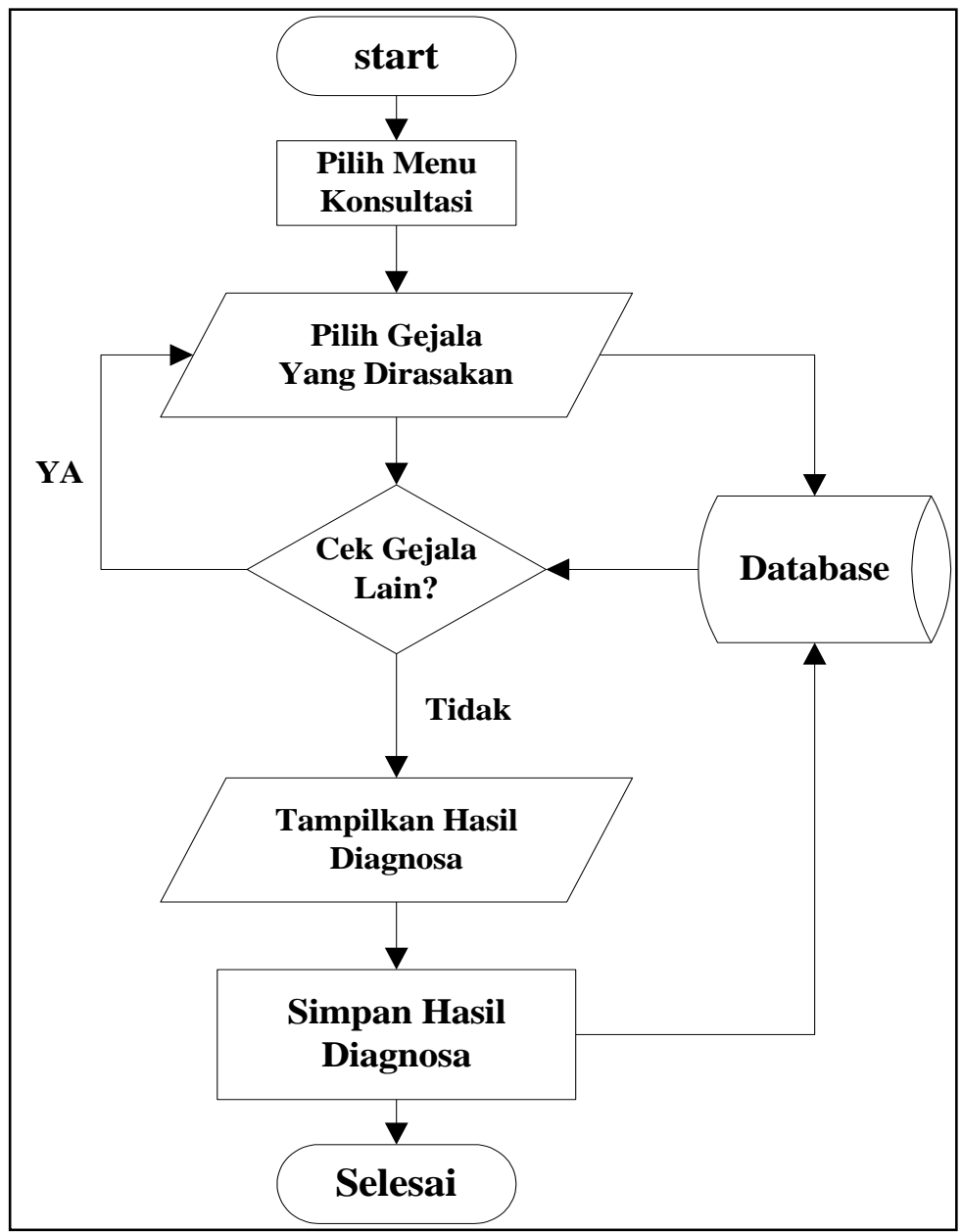

\section{Gambar 6. Flowchart Diagnose Defisiensi Unsur Hara}

\subsection{Penyajian Fakta dan Aturan}

Berdasarkan representasi pengetahuan untuk mendiagnosa defisiensi unsur hara pada tanaman kopi maka disusun daftar aturan (rule) sebagai berikut:

Tabel 2. Penyajian Fakta dan Aturan Diagnosa Defisiensi Unsur Hara

\begin{tabular}{|l|}
\hline \multicolumn{1}{|c|}{ Kaidah IF } \\
\hline IF \\
Klorosis pada daun muda dan klorotik pada daun tua = True, \\
AND Daun muda yang berubah warna menjadi hijau pucat = True, \\
AND Pertumbuhan tunas akan terhambat \\
THEN = Defisiensi Unsur Nitrogen (N)
\end{tabular}




\begin{tabular}{|l}
\hline \multicolumn{1}{|c|}{ Kaidah IF } \\
\hline TF \\
Tulang daun tua akan menjadi kuning terang $=$ True, \\
AND Menyisakan sedikit daun yang berwarna hijau gelap diantara \\
pertulangan daun = True, \\
AND Muncul bercak kecoklatan tanda matinya sel jaringan daun yang dapat \\
melebar = True, \\
AND Perumbuhan akar akan terhambat \\
THEN = Defisiensi Unsur Fosfor (P) \\
\hline IF
\end{tabular}

Bagian tepi daun tua akan menguning diikuti dengan munculnya bintik coklat (nekrotik) $=$ TRUE, $A N D$ Bintik melebar disepanjang tepi daun dengan tepi gelap yang dikelilingi warna kuning $=$ TRUE, $A N D$ Namun bagian pertulangan daun tetap berwarna hijau THEN = Defisiensi Unsur Kalium (K)

\subsection{Runut Maju (Forward Chaining)}

Konsep runut maju (Forward Chaining) melakukan proses yang berawal dari sekumpulan data yang kemudian dilakukan inferensi sesuai dengan aturan yang diterapkan sehingga kesimpulan yang didapat bisa optimal. Untuk mendapatkan hasil keputusan yang sesuai mesin inferensi akan melakukan proses looping.

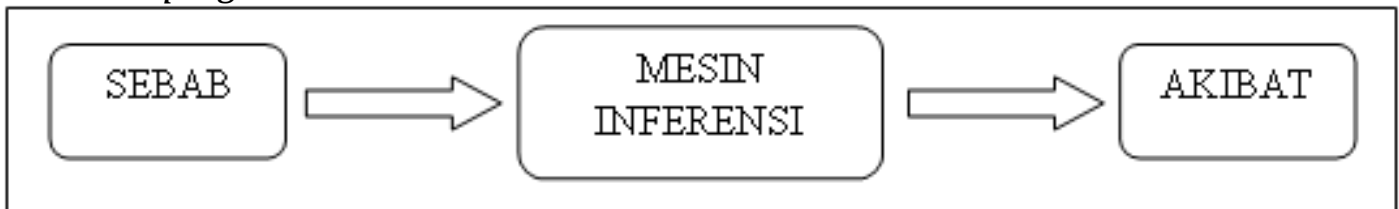

\section{Gambar 7. Proses Infrensi Forward Chaining}

Konsep Forward Chaining sengaja dipilih karena memiliki kelebihan diantaranya metode ini mampu memasukkan data baru kedalam tabel database infrensi serta kemungkinan untuk melakukan perubahan sumber Infrensi. Berikut akan di jelaskan rule dari Forward Chaining.

1. IF Klorosis pada daun muda dan klorotik pada daun tua (G1) dengan nilai $\mathrm{MB}=1$ dan nilai $\mathrm{MD}=0,2 \boldsymbol{T R U E}, \boldsymbol{A N D}$ Daun muda yang berubah warna menjadi hijau pucat (G2) dengan nilai $\mathrm{MB}=0,8$ dan Nilai $\mathrm{MD}=0,3 \boldsymbol{T R U E}$, AND Pertumbuhan tunas akan terhambat (G3) dengan nilai MB $=1$ dan Nilai MD = 0,3 TRUE

THEN = Defisiensi Unsur Nitrogen $(\mathrm{N})$

2. IFseperti : Tulang daun tua akan menjadi kuning terang (G4) dengan nilai $\mathrm{MB}=1$ dan nilai MD = 0,3 TRUE, $\boldsymbol{A N D M e n y i s a k a n ~ s e d i k i t ~ d a u n ~ y a n g ~}$ 
berwarna hijau gelap diantara pertulangan daun (G5) dengan nilai MB = 0,8 dan nilai MD $=0,5 \quad \boldsymbol{T R} \boldsymbol{E} \boldsymbol{E}, \boldsymbol{A N D M u n c u l}$ bercak kecoklatan tanda matinya sel jaringan daun yang dapat (G6) dengan nilai $\mathrm{MB}=1$ dan nilai $\mathrm{MD}=0,2$ TRUE, $\boldsymbol{A N D}$ Perumbuhan akar akan terhambat (G7) dengan nilai $\mathrm{MB}=0,6$ dan nilai $\mathrm{MD}=0,2$ TRUE

THEN= defisiensi unsur Fosfor $(\mathrm{P})$

3. IFBagian tepi daun tua akan menguning, muncul bintik coklat (nekrotik) (G8) dengan nilai $\mathrm{MB}=1$ dan nilai MD = 0,2 TRUE, ANDBintik melebar disepanjang tepi daun dengan tepi gelap yang dikelilingi warna kuning (G9) dengan nilai $\mathrm{MB}=1$ dan nilai $\mathrm{MD}=0,2 \boldsymbol{T R U E}, \boldsymbol{A N D}$ Namun bagian pertulangan daun tetap berwarna hijau (G10) dengan nilai $\mathrm{MB}=0,8$ dan nilai $\mathrm{MD}=0,2 \boldsymbol{T R U E}$

THEN = Defisiensi Unsur Kalium (K)

\subsection{Perhitungan Metode Certainty Factor}

Perhitungan metode Certainty Factor dilakukan secara manual, dimana didalamnya termasukjenis-jenis defisiensi unsur hara yang diketahui gejalanya. Klorosis pada daun muda dan klorotik pada daun tua (G1) dengan nilai MB = 1 dan nilai $\mathrm{MD}=0,2$, Daun muda yang berubah warna menjadi hijau pucat (G2) dengan nilai $\mathrm{MB}=0,8$ dan Nilai $\mathrm{MD}=0,3$, Pertumbuhan tunas akan terhambat (G3) dengan nilai $\mathrm{MB}=1$ dan Nilai $\mathrm{MD}=0,3$

Tulang daun tua akan menjadi kuning terang (G4) dengan nilai MB $=1$ dan nilai $\mathrm{MD}=0,3$, Menyisakan sedikit daun yang berwarna hijau gelap diantara pertulangan daun (G5) dengan nilai $\mathrm{MB}=0,8$ dan nilai $\mathrm{MD}=0,5$, Muncul bercak kecoklatan tanda matinya sel jaringan daun yang dapat (G6) dengan nilai $\mathrm{MB}=1$ dan nilai $\mathrm{MD}=0,2$. Perumbuhan akar akan terhambat (G7) dengan nilai $\mathrm{MB}=$ 0,6 dan nilai $\mathrm{MD}=0,2$

Bagian tepi daun tua akan menguning, muncul bintik coklat (nekrotik) (G8) dengan nilai $\mathrm{MB}=1$ dan nilai $\mathrm{MD}=0,2$, Bintik melebar disepanjang tepi daun dengan tepi gelap yang dikelilingi warna kuning (G9) dengan nilai $\mathrm{MB}=1$ dan nilai $\mathrm{MD}=0,2$, Namun bagian pertulangan daun tetap berwarna hijau (G10) dengan nilai $\mathrm{MB}=0,8$ dan nilai $\mathrm{MD}=0,2$ Berikut tabel gejala dan jenis defisiensi unsur hara.

Tabel 3. Nilai MB (Measure Of Belief) dan MD (Measure of Disbelief)

\begin{tabular}{|c|c|c|c|c|c|c|c|c|}
\hline \multirow{2}{*}{$\begin{array}{l}\text { Kode } \\
\text { gejala }\end{array}$} & \multicolumn{2}{|c|}{ Nitrogen (N) } & \multirow{2}{*}{$\begin{array}{l}\text { Kode } \\
\text { gejala }\end{array}$} & \multicolumn{2}{|c|}{ Fosfor (P) } & \multirow{2}{*}{$\begin{array}{l}\text { Kode } \\
\text { gejala }\end{array}$} & \multicolumn{2}{|c|}{ Kalium (K) } \\
\hline & MB & MD & & MB & MD & & MB & MD \\
\hline G01 & 1 & 0,2 & G04 & 1 & 0,3 & G08 & 1 & 0,2 \\
\hline G02 & 0,8 & 0,3 & G05 & 0,8 & 0,5 & G09 & 1 & 0,2 \\
\hline G03 & 1 & 0,3 & G06 & 1 & 0,2 & G10 & 0,8 & 0,2 \\
\hline & & & G07 & 0,6 & 02 & & & \\
\hline
\end{tabular}


Dari data diatas terdapat gejala yang didalamnya terdapat jenis Defisiensi Unsur hara : Nitrogen (N), Fosfor (P), Kalium (K)

\subsubsection{Melakukan Perhitungan Certainty Factor.}

Berikut ini adalah perhitungan dari metode certainty factor.

a. Nitrogen $(\mathrm{N})$

$$
\begin{aligned}
\mathrm{MB}\left(\mathrm{h}, \mathrm{G} 1^{\wedge} \mathrm{G} 2\right) & =\mathrm{MB}(\mathrm{h}, \mathrm{G} 1)+\mathrm{MB}(\mathrm{h}, \mathrm{G} 2) \times(1-\mathrm{MB}[\mathrm{h}, \mathrm{G} 1]) \\
& =1+0.8 \times(1-1) \\
& =1 \\
\mathrm{MB}\left(\mathrm{h},\left(\mathrm{G} 1^{\wedge} \mathrm{G} 2\right)^{\wedge} \mathrm{G} 3\right) & =\mathrm{MB}\left(\mathrm{h}, \mathrm{G} 1^{\wedge} \mathrm{G} 2\right)+\mathrm{MB}(\mathrm{h}, \mathrm{G} 3)^{*}\left(1-\mathrm{MB}\left[\mathrm{h}, \mathrm{G} 1^{\wedge} \mathrm{G} 2\right]\right) \\
& =1+1 \times(1-1) \\
& =1 \\
\mathrm{MD}\left(\mathrm{h}, \mathrm{G} 1^{\wedge} \mathrm{G} 2\right) & =\mathrm{MD}(\mathrm{h}, \mathrm{G} 1)+\mathrm{MD}(\mathrm{h}, \mathrm{G} 2)^{*}(1-\mathrm{MD}[\mathrm{h}, \mathrm{G} 1]) \\
& =0.2+0.3 \times(1-0.2) \\
\mathrm{MD}\left(\mathrm{h},\left(\mathrm{G} 1^{\wedge} \mathrm{G} 2\right)^{\wedge} \mathrm{G} 3\right) & =0.44 \\
& =\mathrm{MD}\left(\mathrm{h}, \mathrm{G} 1^{\wedge} \mathrm{G} 2\right)+\mathrm{MD}(\mathrm{h}, \mathrm{G} 3)^{*}(1-\mathrm{MD}[\mathrm{h}, \mathrm{G} 1 \wedge \mathrm{G} 2]) \\
& =0.44+0.3 \times(1-0.44) \\
& =0.608
\end{aligned}
$$

Hasilnya MB-MD untuk gejala G1, G2 dan G3

b. Fosfor (P)

$$
\begin{array}{ll}
\mathrm{CF} & =1-0.608 \\
\mathrm{CF} & =0.392
\end{array}
$$

$$
\begin{aligned}
\mathrm{MB}\left(\mathrm{h}, \mathrm{G} 4^{\wedge} \mathrm{G} 5\right) & =\mathrm{MB}(\mathrm{h}, \mathrm{G} 4)+\mathrm{MB}(\mathrm{h}, \mathrm{G} 5) \times(1-\mathrm{MB}[\mathrm{h}, \mathrm{G} 4]) \\
& =1+0.8 \times(1-1) \\
& =1 \\
\mathrm{MB}\left(\mathrm{h},\left(\mathrm{G} 4^{\wedge} \mathrm{G} 5\right)^{\wedge} \mathrm{G} 6\right) & =\mathrm{MB}\left(\mathrm{h}, \mathrm{G} 4^{\wedge} \mathrm{G} 5\right)+\mathrm{MB}(\mathrm{h}, \mathrm{G} 6)^{*}\left(1-\mathrm{MB}\left[\mathrm{h}, \mathrm{G} 4^{\wedge} \mathrm{G} 5\right]\right) \\
& =1+1 \times(1-1) \\
& =1 \\
\left.\mathrm{MB}\left(\mathrm{h},\left(\mathrm{G} 4^{\wedge} \mathrm{G} 5\right)^{\wedge} \mathrm{G} 6\right)^{\wedge} \mathrm{G} 7\right) & =\mathrm{MB}\left(\mathrm{h},\left(\mathrm{G} 4^{\wedge} \mathrm{G} 5\right)^{\wedge} \mathrm{G} 6\right)+\mathrm{MB}(\mathrm{h}, \mathrm{G} 7)^{*} \\
& \left.\left(1 \mathrm{MB}\left[\mathrm{h},\left(\mathrm{G} 4^{\wedge} \mathrm{G} 5\right)^{\wedge} \mathrm{G} 6\right)^{\wedge} \mathrm{G} 7\right]\right) \\
& =1+0,6 \times(1-1) \\
& =1 \\
& =\mathrm{MD}(\mathrm{h}, \mathrm{G} 4)+\mathrm{MD}(\mathrm{h}, \mathrm{G} 5) \times(1-\mathrm{MD}[\mathrm{h}, \mathrm{G} 4]) \\
& =0.3+0.5 \times(1-0.3) \\
\mathrm{MD}\left(\mathrm{h}, \mathrm{G} 4^{\wedge} \mathrm{G} 5\right) & 0.65 \\
& =\mathrm{MD}\left(\mathrm{h}, \mathrm{G} 4^{\wedge} \mathrm{G} 5\right)+\mathrm{MD}(\mathrm{h}, \mathrm{G} 6)^{*}\left(1-\mathrm{MD}\left[\mathrm{h}, \mathrm{G} 4^{\wedge} \mathrm{G} 5\right]\right) \\
\mathrm{MD}\left(\mathrm{h},\left(\mathrm{G} 4^{\wedge} \mathrm{G} 5\right)^{\wedge} \mathrm{G} 6\right) & 0.65+0.2 \times(1-0.65) \\
& =0.72 \\
\left.\mathrm{MD}\left(\mathrm{h},\left(\mathrm{G} 44^{\wedge} \mathrm{G} 5\right)^{\wedge} \mathrm{G} 6\right) \wedge \mathrm{G} 7\right) & =\mathrm{MD}\left(\mathrm{h},\left(\mathrm{G} 44^{\wedge} \mathrm{G} 5\right)^{\wedge} \mathrm{G} 6\right)+\mathrm{MD}(\mathrm{h}, \mathrm{G} 7)^{*}(1-\mathrm{MD}[\mathrm{h}, \\
\left.\left.\left.\left(\mathrm{G} 4^{\wedge} \mathrm{G} 5\right)^{\wedge} \mathrm{G} 6\right)\right]\right) & \\
= & 0.72+0.2 \times(1-0.72) \\
= & 0.776
\end{aligned}
$$

Hasilnya MB-MD untuk gejala G4, G5, G6 dan G7 
c. $\operatorname{Kalium}(\mathrm{K})$

$$
\begin{array}{ll}
\mathrm{CF} & =1-0.776 \\
\mathrm{CF} & =0.224
\end{array}
$$

$$
\begin{aligned}
\mathrm{MB}\left(\mathrm{h}, \mathrm{G} 8^{\wedge} \mathrm{G} 9\right) & =\mathrm{MB}(\mathrm{h}, \mathrm{G} 8)+\mathrm{MB}(\mathrm{h}, \mathrm{G} 9) \times(1-\mathrm{MB}[\mathrm{h}, \mathrm{G} 8]) \\
& =1+1 \times(1-1) \\
& =1 \\
\mathrm{MB}\left(\mathrm{h},\left(\mathrm{G} 8^{\wedge} \mathrm{G} 9\right)^{\wedge} \mathrm{G} 10\right) & =\mathrm{MB}\left(\mathrm{h}, \mathrm{G} 8^{\wedge} \mathrm{G} 9\right)+\mathrm{MB}(\mathrm{h}, \mathrm{G} 10)^{*}\left(1-\mathrm{MB}\left[\mathrm{h}, \mathrm{G} 8^{\wedge} \mathrm{G} 9\right]\right) \\
& =1+0.8 \times(1-1) \\
& =1 \\
\mathrm{MD}\left(\mathrm{h}, \mathrm{G} 8^{\wedge} \mathrm{G} 9\right) & =\mathrm{MD}(\mathrm{h}, \mathrm{G} 8)+\mathrm{MD}(\mathrm{h}, \mathrm{G} 9) \times(1-\mathrm{MD}[\mathrm{h}, \mathrm{G} 8]) \\
& =0,2+0.2 \times(1-0.2) \\
\mathrm{MD}\left(\mathrm{h},\left(\mathrm{G} 8^{\wedge} \mathrm{G} 9\right)^{\wedge} \mathrm{G} 10\right) & =0.36 \\
& =\mathrm{MD}\left(\mathrm{h}, \mathrm{G} 8^{\wedge} \mathrm{G} 9\right)+\mathrm{MD}(\mathrm{h}, \mathrm{G} 10)^{*}\left(1-\mathrm{MD}\left[\mathrm{h}, \mathrm{G} 8^{\wedge} \mathrm{G} 9\right]\right) \\
& =0.36+0.2 \times(1-0.36) \\
& =0.488
\end{aligned}
$$

Hasilnya MB-MD untuk gejala G15, G16 dan G17

$$
\begin{array}{ll}
\mathrm{CF} & =1-0.488 \\
\mathrm{CF} & =0.512
\end{array}
$$

\subsubsection{Hasil Perhitungan Certainty Factor.}

Berikut ini adalah hasil perhitungan dari metode certainty factor.

a. Nitrogen $(\mathrm{N})$

Nilai $\mathrm{CF}$ adalah $=0.392$

b. Fosfor (P)

Nilai $\mathrm{CF}$ adalah $=0.224$

c. Kalium (K)

Nilai $\mathrm{CF}$ adalah $=0.512$

Mencari Nilai Maximal

\subsection{2}

$\operatorname{Max} \mathbf{0 . 2 2 4}=\mathbf{0 . 5 1 2}$

0.512

Hasil yang akan di capai nantinya yaitu website sistem pakar yang nantinya diharapkan dapat membantu masyarakat khususnya para petani kopi dalam mengetahui unsur hara apa yang mengalami defisiensi pada tanaman kopi mereka. Sehingga masyarakat maupun petani bisa dengan mudah mengetahui defisiensi unsur hara pada tanaman kopi dengan hanya membuka situs web sistem pakar ini dimana pun berada. Hal ini akan membuat biaya konsultasi dengan pakar akan semakin murah, karna masyarakat maupun petani tidak harus berjumpa secara langsung dengan pakar, mengingat hampir semua masyarakat maupun petani biasanya tinggal di daerah pedesaan ataupun di daerah. Sedangkan keberadaan seorang pakar biasanya tinggal maupun berada di daerah perkotaan saja, sehingga akses untuk menemui seorang pakar sangatlah sulit 
dilakukan. Maka dengan adanya website sistem pakar ini nantinya diharapkan dapat menjangkau daerah maupun wilayah pelosok tanpa harus mendatangkan seoerang pakar.

\subsection{Tampilan Website Sistem Pakar Identifikasi Defisiensi Unsur Hara}

Tampilan website sistem pakar di rancang semudah mungkin untuk penggunaanya (user friendly) agar memudahkan masyarakat maupun petani dalam menggunakan sistem pakar tersebut. Bahasa maupun tampilan menu utama akan di rancang semenarik mungkin agar memikat hati pengguna dalam menggunakan sistem pakar identifikasi defisiensi unsur hara pada tanaman kopi. Adapun form menu utama yang terdapat pada website sistem pakar identifikasi defisiensi unsur hara pada tanaman kopi nantinya terdiri dari menu login sebagai admin, menu login sebagai user, menu utama, menu about (tentang website), menu daftar gejala, menu daftar jenis penyakit (defisiensi), menu diagnose. Berikut adalah gambar tampilan form menu utama dari website sistem pakar identifikasi defisiensi unsur hara pada tanaman kopi :

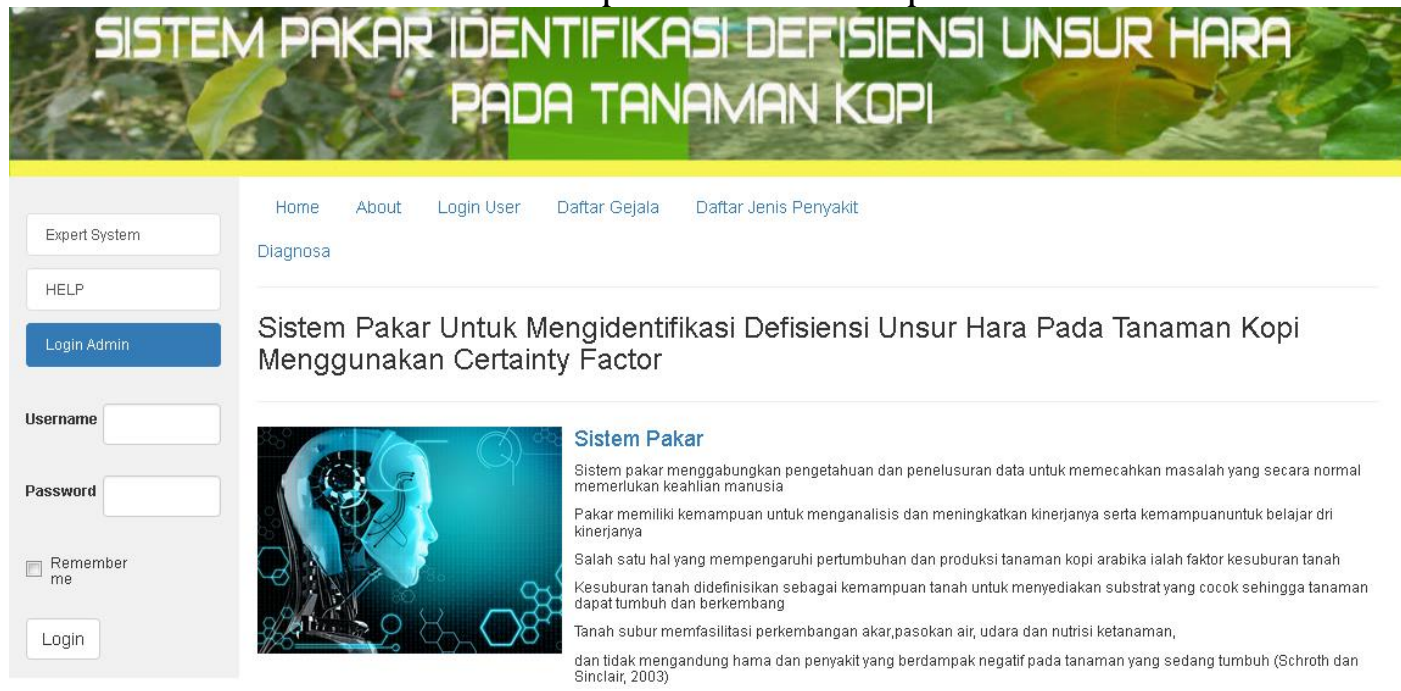

Gambar 8. Tampilan Menu Utama Sistem Pakar Identifikasi Defisiensi Unsur Hara Pada Tanaman Kopi.

\subsection{Tampilan Database Gejala}

Daftar gejala defisiensi unsur hara pada tanaman kopi akan di sajikan dalam bentuk database. Gejala yang ada di database didapatkan dari hasil penelitian yang dilakukan oleh seorang pakar, dalam hal ini pakar tanaman. Pasien atau petani dapat memilih gejala mana yang sesuai yang dialami oleh tanaman milik petani tersebut. Pasien atau petani dapat mengetahui gejala yang timbul dengan cara mengamati dari perkembangan daun tanaman kopi sehingga bisa mendapatkan hasil yang bisa disesuaikan dengan gejala yang sudah di paparkan oleh seorang pakar. 


\begin{tabular}{|c|l|}
\hline Kode Gejala - & \multicolumn{1}{c}{ Nama Gejala } \\
\hline 01 & Klorosis pada daun muda dan klorotik pada daun tua \\
\hline 02 & Daun muda yang berubah warna menjadi hijau pucat \\
\hline 03 & Pertumbuhan tunas akan terhambat \\
\hline 04 & Tulang daun tua akan menjadi kuning terang \\
\hline 05 & Menyisakan sedikit daun yang berwarna hijau gelap diantara pertulangan daun \\
\hline 06 & Muncul bercak kecoklatan tanda matinya sel jaringan daun yang dapat melebar \\
\hline 07 & Perumbuhan akar akan terhambat \\
\hline 08 & Bagian tepi daun tua akan menguning diikuti dengan munculnya bintik coklat (nekrotik) \\
\hline 09 & Bintik melebar disepanjang tepi daun dengan tepi gelap yang dikelilingi warna kuning \\
\hline 10 & Namun bagian pertulangan daun tetap berwarna hijau \\
\hline
\end{tabular}

\section{Gambar 9. Tampilan Database Gejala.}

\subsection{Tampilan jenis defisiensi unsur hara}

Untuk jenis defisiensi unsur hara pada tanaman kopi juga disajikan dalam bentuk database. Ada 3 jenis defisiensi unsur hara yang bisa diketahui yaitu : Nitrogen, Posfor dan Kalium. Ketiga jenis unsur hara ini yang di temukan pada saat penelitian dilapangan atau dilokasi penelitian. Berikut tampilan jenis defisiensi unsur hara tersebut :

\begin{tabular}{ll} 
Kode Jenis Defisiensi & Jenis Defisiensi \\
\hline U 001 & Nitrogen (N) \\
\hline U 002 & Posfor (P) \\
U 003 & Kalium (K)
\end{tabular}

Gambar 10. Tampilan Database 3 jenis defisiensi.

\section{SIMPULAN}

Sistem pakar berbasis web pada laporan hasil penelitian ini merupakan hasil yang di dapat pada saat penelitian di lokasi perkebunan kopi rakyat didaerah tanah karo dan lokasi tersebut terletak di dataran tinggi. Dari hasil penelitian yang dilakukan oleh pakar didapatkan 3 jenis defisiensi unsur hara yaitu : Nitrogen, Posfor dan Kalium. Perbedaan lokasi dapat menentukan perbedaan jenis defisiensi unsur hara pada tanaman kopi. Sistem pakar ini masih tergolong sederhana bisa dikembangkan lagi, contohnya pengembangan pada jenis defisiensi yang lain dan bisa juga dengan tanaman jenis lain. Penentuan nilai certainty factor haruslah dilakukan oleh seorang pakar, sehingga dapat didapatkan hasil yang lebih maksimal dan akurat.

\section{DAFTAR PUSTAKA}

[1] Rohman dan Fauziah (2008) .Rancang bangun aplikasi sistem pakar untuk menentukan jenis gangguan perkembangan pada ana Media Informatika, Vol. 6, No. 1

[2] Sulistyohati, Hidayat (2008). Aplikasi system pakar 235okum235ta penyakit ginjal dengan metode dempster-shape. Seminar Nasional Aplikasi Teknologi Informasi (SNATI 2008) ISSN : 10907-5022. 
[3] Sukarsa dan Wisswani (2009). Rancang bengun system pakar untuk perbaikan Kecepatan Dan kegagalan koneksi peralatan ekternal pada personal compute. Jurnal Teknologi Elektro.vol.8 Nomor. 1.

[4] Sri et.al (2012). Sistem pakar penyakit kulit pada manusia menggunakan metode Certainty factor berbasis web. Seminar nasional teknologi informasi, komunikasi dan industry (SNTIKI) 4. ISSN : 2085-9902.

[5] Tuswanto dan abdul (2013). Sistem pakar untuk mendiagnosa hama dan penyakit Tanaman bawang merah menggunakan certainty factor. Jurnal sarjana teknik informatika vol.1 nomor1.

[6] Encep et.al (2014). Perancangan sistem pakar diagnosis penyakit syaraf pada wajah Berbasis web. Jurnal Algoritma. Vol 11. Nomor 1.

[7] Poni dan Abdul (2014). Sistem pakar mendiagnosa jenis penyakit stroke menggunakan metode certainty facto. Jurnal Sarjana Teknik Informatika. Vol.2. Nomor 1.

[8] Asiaman dan Harvei (2015). Sistem pakar 236okum236ta penyakit pada tanaman coklat/kakao Dengan metode certainty facto. Majalah ilmiah informasidan teknologi ilmiah (INTI). Vol.V. Nomor 2.

[9] Mustafa, M., Ahmad, A., Ansar, M., \& Syafiuddin, M. (2012). Dasar-Dasar Ilmu Tanah (Hibah Buku Ajar). Makassar: Fakultas Pertanian Universitas Hasanuddin.

[10] Nagao, M., Kobayashi, K. ., \& Yasuda, G. . (1986). Mineral Deficiency Symptoms of Coffee. Hawai: Hawaii Institute of Tropical Agriculture and Human Resources.

[11] Sipahutar, A. H. (2014). Kajian Sifat Fisika dan Kimia Tanah yang Mempengaruhi Sebaran Akar Kopi Arabika (Coffea 236okum236t L.) pada Ketinggian Tempat yang Berbeda di Tanah Inceptisol Kecamatan Lintong Nihuta. 